\title{
Impactos Socioeconômicos, Ambientais e Tecnológicos Causados pela Instalação dos Parques Eólicos no Ceará
}

\author{
Mônica Antonizia de Sales $\operatorname{Costa}^{1}$ (D), Monilson de Sales $\operatorname{Costa}^{1}$, Maria Monizia de Sales Costa $^{1}$, \\ Marcos Antônio Tavares Lira ${ }^{2}$ \\ ${ }^{1}$ Mestrado em Climatologia e Aplicações nos Países da CPLP, Universidade Estadual do Ceará, \\ Fortaleza, CE, Brasil. \\ ${ }^{2}$ Departamento de Engenharia Elétrica, Universidade Federal do Piauí, Teresina, PI, Brasil.
}

Recebido em: 30 de Maio de 2019 - Aceito em: 27 de Junho de 2019

\begin{abstract}
Resumo
O Estado do Ceará se destaca no processo de produção de energia proveniente dos ventos por possuir posição geográfica privilegiada na geração de energia eólica. Esse trabalho consiste em apresentar os impactos ambientais, sociais, econômicos e tecnológicos originados com a implantação e operação das Usinas Eólicas no litoral cearense através da análise comparativa entre os Parques Eólicos de Beberibe e de Fleixeiras I. Os principais impactos socioambientais detectados foram: diminuição da fauna e da flora, desgastes das vias de acesso, produção de ruídos, descaracterização da paisagem natural, limitação do direito de "ir e vir", fissuras em casas. Os impactos econômicos foram mais expressivos durante a construção dos parques, diminuindo gradativamente com o passar dos anos. Já nos aspectos tecnológicos pode-se perceber que quanto maior a altura das torres e o diâmetro do rotor, maior a quantidade de energia gerada. Esta investigação teve característica de pesquisa descritiva e exploratória, descrevendo-os a partir dos métodos qualitativo e quantitativo. Foram necessários estudos dirigidos para compreender os impactos provocados pela fonte de energia eólica, bem como sugerir alternativas de mitigação do agravamento das alterações climáticas ocasionadas pelo efeito estufa no planeta.
\end{abstract}

Palavras-chave: energia eólica, litoral cearense, impactos, mudanças climáticas.

\section{Ocioeconomic, Environmental and Technological Impacts Caused by the Installation of Wind Parks in Ceará}

\begin{abstract}
The State of Ceará stands out in the process of producing energy from the wind because it has a privileged geographical position in the generation of wind energy. This work consists in presenting the environmental, social, economic and technological impacts caused by the implementation and operation of the Wind Power Plants in the coast of Ceará through a comparative analysis between the Wind Farms of Beberibe and Fleixeiras I. The main socioenvironmental impacts detected were: fauna and flora, wear and tear of access roads, production of noise, de-characterization of the natural landscape, limitation of the right to "come and go", cracks in houses. The economic impacts were more significant during the construction of the parks, gradually decreasing over the years. In the technological aspects, it can be seen that the bigger the height of the towers and the diameter of the rotor, the greater the amount of energy generated. This research had characteristic of descriptive and exploratory research, describing them from the qualitative and quantitative methods. Studies were needed to understand the impacts of the wind energy source, as well as to suggest alternatives to mitigate the worsening global warming caused by the greenhouse effect on the planet.
\end{abstract}

Keywords: wind energy, coast of Ceará, impacts, climate changes.

Autor de correspondência: Mônica Antonizia de Sales Costa, monica.antonizia@gmail.com. 


\section{Introdução}

Mundialmente, a fonte energética mais utilizada para a produção de energia elétrica é proveniente de fontes fósseis e não renováveis como o petróleo, o carvão mineral e o gás natural (Freitas e Dathein, 2013). As grandes dependências de fontes não renováveis de energia têm acarretado, além da preocupação permanente com o seu esgotamento, a emissão de gases tóxicos e poluentes. Dos gases liberados para a atmosfera, os mais preocupantes são os gases do efeito estufa (Nascimento, 2016; Drumm, 2014). Para incentivar o uso de formas de energia mais limpas, esforços governamentais e não governamentais mundiais buscam substituir combustíveis fósseis por tecnologias menos poluentes visando reduzir a emissão e, com isso, melhorar a qualidade do ar, proteger a saúde e minimizar os efeitos climáticos (Anenberg, 2013).

As energias renováveis, tornaram-se um importante recurso para o desenvolvimento sustentável, que vêm, através do tempo, ganhando maior força no seu crescimento e aplicação (Freitas, 2015). De modo geral, o cenário de progresso das fontes de energias renováveis é algo promissor, uma vez que, o potencial é elevado. Nesse contexto de energia, vale ressaltar que o Brasil já possui uma das matrizes mais renováveis do mundo. Segundo a Empresa de Pesquisa Energética (2018), o Brasil dispõe de uma matriz elétrica de origem predominantemente renovável ( $80,4 \%$ da oferta interna), com destaque para a fonte hídrica ( $65,2 \%$ da oferta interna).

Verifica-se, que no cenário dos empreendimentos de energia no mundo, a energia eólica vem se tornando uma das grandes possibilidades para o futuro, por sua qualidade ambiental e por sua abundante presença em muitos locais do Planeta (Farias, 2016). A produção de eletricidade no Brasil a partir da fonte eólica alcançou $42.373 \mathrm{GWh}$ em 2017 , equivalente a um aumento de $26,5 \%$ em relação ao ano de 2016, quando se atingiu $33.489 \mathrm{GWh}$ (EPE, 2018). Nessa circunstância, destaca-se, que em 2017, a potência instalada para geração eólica no país expandiu 21,3\%, atingido 12,36 W ao final de 2017 (EPE, 2018).

No Brasil, em 2017, a região Nordeste foi a que apresentou maior representatividade na geração de energia proveniente da fonte eólica com 84\% (33,99 TWh), seguido da região da região Sul com $14,4 \%(5,84 \mathrm{TWh})$ e da região Norte com 1,4\% (0,55 TWh). Os cinco Estados com maior geração nesse período foram: Rio Grande do Norte (13,24 TWh), Bahia (7,79 TWh), Rio Grande do Sul (5,58 TWh), Ceará $(5,10 \mathrm{TWh})$ e Piauí $(4,59 \mathrm{TWh})$ (ABEEÓLICA, 2019).

A energia eólica apresenta inúmeros benefícios quando comparada com as outras fontes energéticas, além de ser uma fonte de energia renovável, não emitir poluentes para a atmosfera e não produz resíduos (EIA, 2018). De modo geral, todas as formas de produção de energia em alguma escala geram impactos de pequena ou grande proporção (JABER, 2013). Em virtude de a instalação dos parques eólicos tornar-se cada vez mais viável, contudo, em alguns casos, os impactos ambientais, sociais, econômicos e tecnológicos provocados por esse tipo de empreendimento são ignorados, pelos agenciadores, durante o período de implantação que se estende no período de operação (Cuadra, 2019).

Os impactos socioambientais associados, tanto à construção quanto à operação de parques eólicos, classificam-se como: interferência na flora e fauna por alteração na cobertura vegetal; a interferência direta na fauna alada por colisão com as pás dos aerogeradores; perturbação no trânsito durante o transporte dos componentes dos aerogeradores; aumento na demanda por serviços e infraestrutura; produção de ruído; alteração na paisagem e aumento da dinâmica econômica. Ressalta-se que a relevância dessas interferências varia com as características regionais e locais dos sítios de implantação dos parques eólicos (Fernandes, 2017; Tolmasquim, 2016; Wang, 2015).

Esse estudo deu-se a partir do desejo de conhecer os verdadeiros aspectos que influenciam na geração de energia por fonte eólica a nível ambiental, social, econômica e tecnológica, bem como investigar se com os passar dos anos essas peculiaridades sofrem alguma modificação, por esse motivo as usinas investigadas entraram em operação nos anos de 2008 e 2014, instaladas nos municípios de Beberibe e de Trairi, respectivamente. Buscando também conhecer e acompanhar o desenvolvimento da tecnologia empregada nesse processo de geração energia.

O objetivo principal deste trabalho é analisar e comparar os aspectos ambientais, sociais, econômicos e tecnológicos originados com a implantação dos parques eólicos geradores de energia elétrica, nas usinas eólicas de Beberibe e Fleixeiras I, nos municípios de Beberibe e Trairi, estado do Ceará.

\section{Materiais e Métodos}

O Parque Eólico de Beberibe (PEB), começou a funcionar em setembro de 2008. Foi construído na Praia das Fontes, na fazenda Uberaba, município de Beberibe. Sua capacidade instalada é de $26 \mathrm{MW}$, composto por 25 aerogeradores com 70 metros de altura e potência de 1,04 MW cada, em um terreno de 61 hectares. O Parque Eólico de Fleixeiras I (PEF), começou a funcionar em janeiro de 2014. Foi construído na localidade de Mundaú, município de Trairi. Sua capacidade instalada é de $30 \mathrm{MW}$, composto por 13 aerogeradores com 80 metros de altura e potência de 2,3 MW cada, em um terreno de 74 hectares.

Foram realizadas visitas para coletas de dados na Superintendência Estadual do Meio Ambiente (SEMACE) para consultas aos documentos de Estudo de Impacto Ambiental (EIA) e Relatório de Impacto Ambiental (RIMA) dos parques eólicos de Beberibe e Fleixeiras I; 
nas prefeituras dos municípios de Beberibe e Trairi para aplicação dos formulários aos gestores de meio ambiente e do turismo; nas Câmaras de Dirigentes Lojistas (CDL) de Beberibe e de Trairi, aos comerciantes e os setores de serviços (pousada e hotéis) e aos nativos que moram nas adjacências das usinas eólicas. Ainda nessa etapa, foi realizada a preparação de formulários e instrumentos utilizados durante as visitas a campo, objetivando uma melhor eficiência e qualidade na captura de dados para segunda etapa da pesquisa.

Como instrumento de pesquisa, foram aplicados os formulários nos municípios de Beberibe e Trairi: 1 formulário para a coordenação da secretaria de meio ambiente de cada município; 1 formulário para secretaria de turismo e cultura de cada município; 1 formulário para o gestor que trabalham na administração dos parques eólicos de Beberibe e de Fleixeiras I (um por usina); 35 formulários para as famílias que moram no entorno do parque eólico de Beberibe (um por família), que representa um total de $41,2 \%$ das famílias ali residentes e 20 formulários para as famílias que moram no entorno parque eólico de Fleixeiras I (um por família), que representa um total de $41,7 \%$ das famílias ali residentes; 20 formulários para os comércios associados a CDL de Beberibe, que representa um total de $60,6 \%$ do comércio do município e 20 formulários para os comércios associados a CDL de Trairi, que representa um total de $54,1 \%$ do comércio do município; 20 formulários para pousadas e hotéis do município de Beberibe, que representa um total de $74,1 \%$ de pousadas e hotéis da região e 20 formulários para pousadas e hotéis da sede do município de Trairi e de flecheiras, que representa um total de $71,43 \%$ de pousadas e hotéis da região. Totalizando 78 formulários aplicados no município de Beberibe e 63 formulários aplicados no município de Trairi.

O formulário 1 foi composto de itens relativos a dados gerais sobre os participantes, questões sobre os impactos ambientais relacionados a fauna e a flora, riscos de acidentes, doenças, interferência no cotidiano da população, alteração no meio físico e visual, como também, os impactos sociais, econômicos e tecnológicos gerados com a construção, instalação e operação dos parques em questão. $\mathrm{O}$ formulário 2 foi composto de itens relativos a qualificação do entrevistado, questões de impactos ambientais resultados da construção e instalação e dos parques eólicos, bem como o aumento de demanda de infraestrutura urbana e de serviço, geração de emprego, atração turísticas e crescimento das cidades.

\section{Resultados e Discussões}

\subsection{Avaliação dos aspectos ambientais}

Foi detectado durante a pesquisa que os impactos ambientais dos parques de geração de energia eólica (Beberibe e Fleixeiras I) foram mais intensos na fase de implantação dos parques. A fase de implantação é constituída pelas etapas de limpeza do terreno, instalação do canteiro de obra, terraplanagem, estaqueamento e construção da base de concreto e montagem dos equipamentos. Os parques eólicos de Beberibe e Fleixeiras I entraram em operação no ano de 2008 e 2014, respectivamente. Nessa perspectiva, foram analisados os principais impactos ambientais ocorridos tanto no período de instalação, como os que se prolongam atualmente em seu período de funcionamento. Os indicadores investigados na dimensão ambiental estão descritos abaixo.

\subsubsection{Impactos provocados à fauna}

Durante a construção do parque eólico a fauna, tanto terrestre como alada, existente nas áreas tende a deixar o seu habitat devido o movimento de máquinas para abertura das vias de acesso, contudo, após a finalização dessas atividades existe a possibilidade delas voltarem para o seu ambiente. De um modo geral, tanto avifauna como os répteis dessas localidades são adaptados a ambientes abertos, devido essa ser a característica do habitat antes da construção dos aerogeradores.

Pelas respostas aos formulários, evidencia-se que tanto as pessoas que moram nas adjacências quanto as que trabalham no parque de Beberibe não tiveram a percepção da presença deste impacto, seja na mortalidade ou diminuição da fauna alada e/ou terrestre. Em contrapartida, os morados do parque de Fleixeiras I percebem a diminuição do número de fauna alada, no caso de pássaros, e da fauna terrestre, no caso do Calango (Tropidurus hispidus), notaram a ausência da fauna em sua comunidade e em suas próprias residências. Na Fig. 1 apresenta-se os percentuais de respostas deste indicador.

\subsubsection{Impactos provocados à flora}

As vegetações predominantes nessas regiões são esparsas de distribuição restrita nas áreas de vegetação pioneira. No PEB apresenta vegetação de tabuleiro, dunas, manguezais, mata ciliar e de lagoa, transição tabuleiro caatinga. No PEF apresenta vegetação pioneira psamófila,

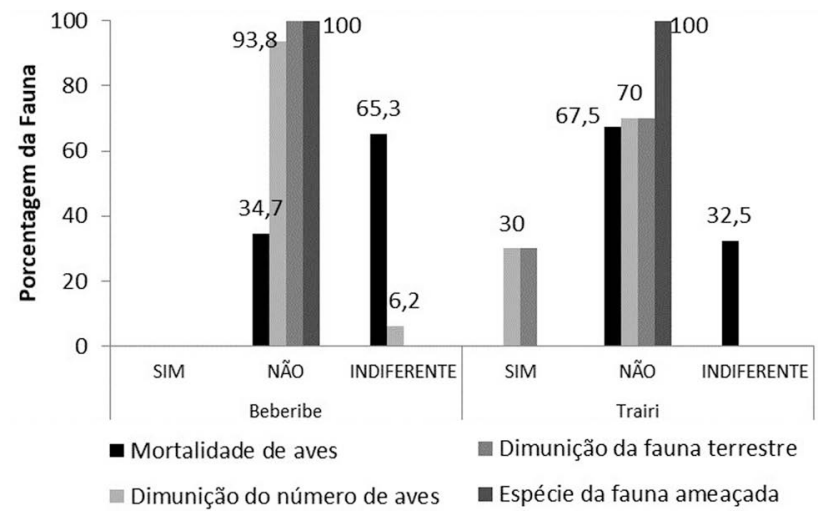

Figura 1 - Impactos provocados à fauna. 
floresta à retaguarda das dunas, vegetação dos tabuleiros litorâneos. Pelas respostas aos formulários, comprova-se que tanto as pessoas que moram nas proximidades quantos as que trabalham nos parques em estudo, identificam que houve a suspensão da vegetação nativa apenas nos arredores das torres e nas estradas de acesso, utilizada para passagem de caminhão para montagem e manutenção das torres, porém essa suspenção acontece em locais pontuais dentro do parque, permitindo a criação da pecuária, por parte dos proprietários das terras. Vale destacar que a população percebeu que há uma diminuição e substituição na vegetação no ambiente de instalação, devido à necessidade de conter os transportes de sedimentos das dunas. Segundo os funcionários do parque de Beberibe, há substituição da vegetação nativa através do replantio de capim de praia (paspalium vaginatum) sobre as dunas para evitar a movimentação dos sedimentos de dunas. Contudo, os entrevistados declaram que não existe espécie da flora ameaçada. Na Fig. 2 apresenta-se os percentuais de respostas deste indicador dos principais impactos provocados à flora com a instalação dos parques eólicos nos dois municípios em estudo.

\subsubsection{Desgastes das vias de acesso}

As vias são construídas com leito de piçarra sobre a superfície das dunas, a terraplanagem foi efetuada em setores para o nivelamento das áreas. As estradas que dão acesso até as usinas foram construídas pelos empresários responsáveis pelos empreendimentos, no entanto, essas estradas beneficiam as populações que residem nas vias de chegada aos parques, melhorando as condições de trafegabilidade e acessibilidades aos centros das cidades. Antes da construção das estradas, não era possível o tráfego de carros até as comunidades do Canaã e do Palmeira, no município de Trairi. Entretanto, sua construção também acarretou alguns prejuízos, principalmente devido à poeira ocasionada e pelo transtorno no período chuvoso devido às poças de lamas que se formam.

Em relação às vias que oferecem acesso ao PEB, configura pela população que mora no entorno, que esse é um dos impactos vivenciados, desde a implantação do até os dias atuais, por ser uma estrada carroçável, com a passagem dos carros, caminhões e do próprio vento que leva muita poeira para as residências, acarretando doenças respiratórias e alérgicas, citada por $57,1 \%$ da população, os outros $42,9 \%$ não sofrem diretamente esses impactos por não morarem próximo à rua principal que dá acesso à usina. Esse impacto também é vivenciado pela população do PEF que totaliza $65 \%$ dos entrevistados, os outros $35 \%$ não vivenciam, porque as casas possuem grande distância da rua principal de circulação. Os percentuais das respostas referentes aos desgastes das vias de acesso estão na Fig. 3 .

\subsubsection{Alterações nos níveis de pressão sonora}

O grande incômodo provocado pelos ruídos quando as residências se localizam próximos aos aerogeradores, e à medida que se mantém um afastamento da fonte geradora, passa ser irrelevante. Consoante informação da população de Beberibe, os ruídos provocados pela usina não são inconvenientes, em virtudes de a residência mais próximas estarem aproximadamente a $500 \mathrm{~m}$ de distância das torres, a população relata que não interfere e nem incomoda as pessoas que vivem na comunidade. Na usina de Fleixeiras I, segundo o RIMA (2010) os aerogeradores estão situados $980 \mathrm{~m}$ de distância da comunidade de Mundaú e $1150 \mathrm{~m}$ da comunidade de Canaã, a maioria dos moradores dessas comunidades relatam que o barulho é

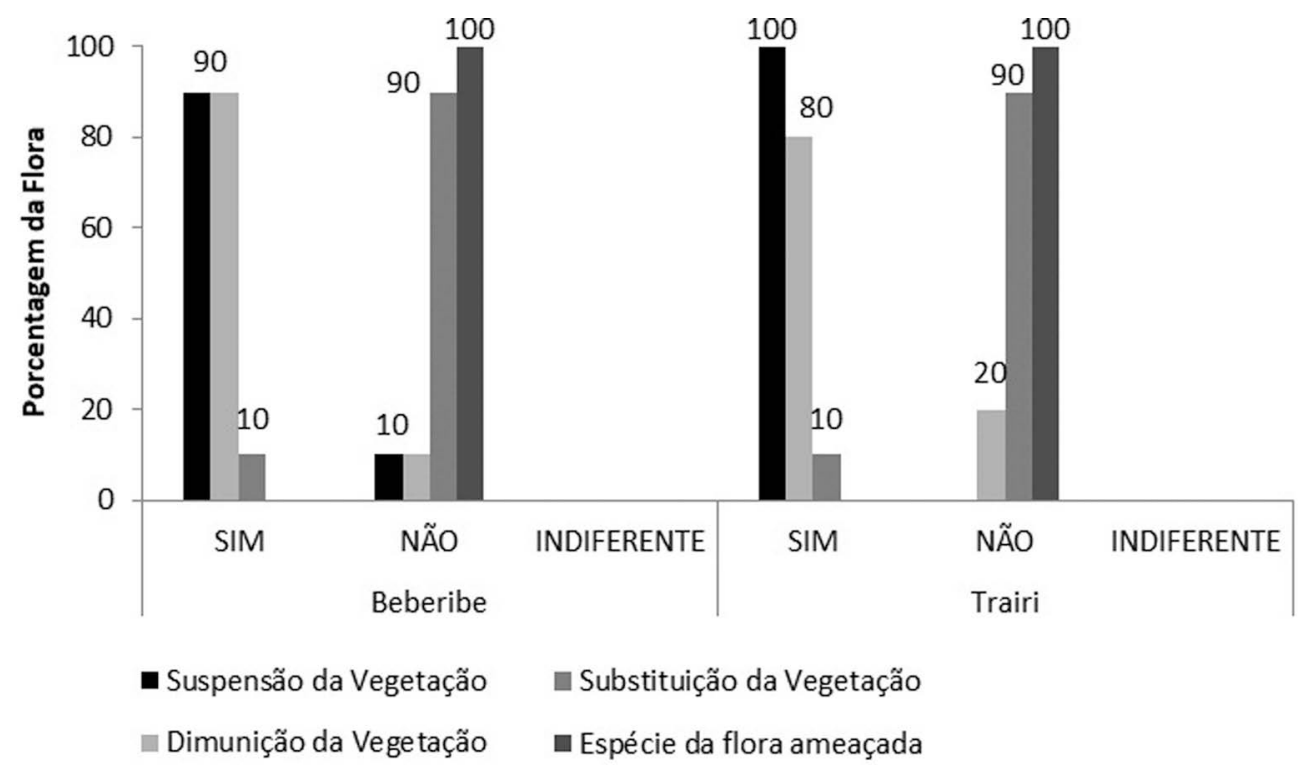

Figura 2 - Impactos provocados à flora. 


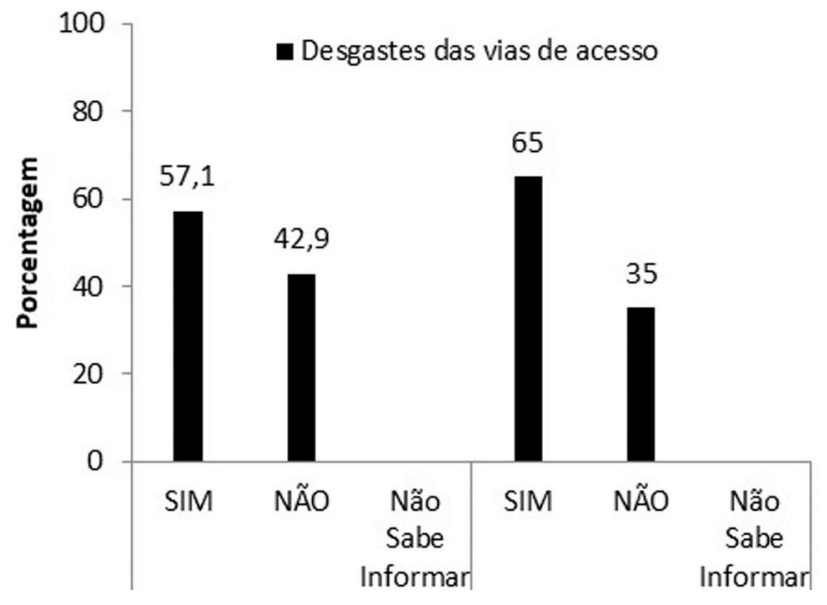

Figura 3 - Desgastes das vias de acesso.

insuportável principalmente no turno da noite, perturbando ao sono. Em contrapartida, devido à proximidade de uma residência isolada com as torres, foi entrevistada uma senhora que necessita de acompanhamento pelos Centros de Atenção Psicossocial (CAPS) por doença adquirida através do barulho provocado pelos aerogeradores, segundo a mesma ela não conseguia dormir, necessitando ingerir remédio controlado. Na Fig. 4 exibe- se os percentuais das respostas referentes à percepção das pessoas quanto a produção de ruído.

\subsubsection{Descaracterização da paisagem natural}

Com a instalação dos aerogeradores nos parques eólicos, houve uma interferência na paisagem natural com a introdução de estruturas que se destacam pelo seu grande porte. No PEB, foram constatados por unanimidade das pessoas que responderam o formulário que os aerogeradores não interferem na beleza cênica e nem na paisagem da região, não causando nenhum efeito paisagístico negativo para os moradores e para as pessoas que visitam a área da usina. Já no PEF existe uma divergência quanto à presença dos aerogeradores considerado para alguns como algo benéfico, e para outros como um elemento adverso na paisagem. Em relação ao impacto visual que provoca achatamento das dunas, nos PEB e PEF, são apenas nos locais onde foram construídas as torres eólicas. Na Fig. 5 são mostrados os percentuais das respostas referentes à descaracterização da paisagem natural.

\subsubsection{Interferência na paisagem}

Através da compactação de dunas e alterações na topografia do relevo local, o ambiente eólico litorâneo é

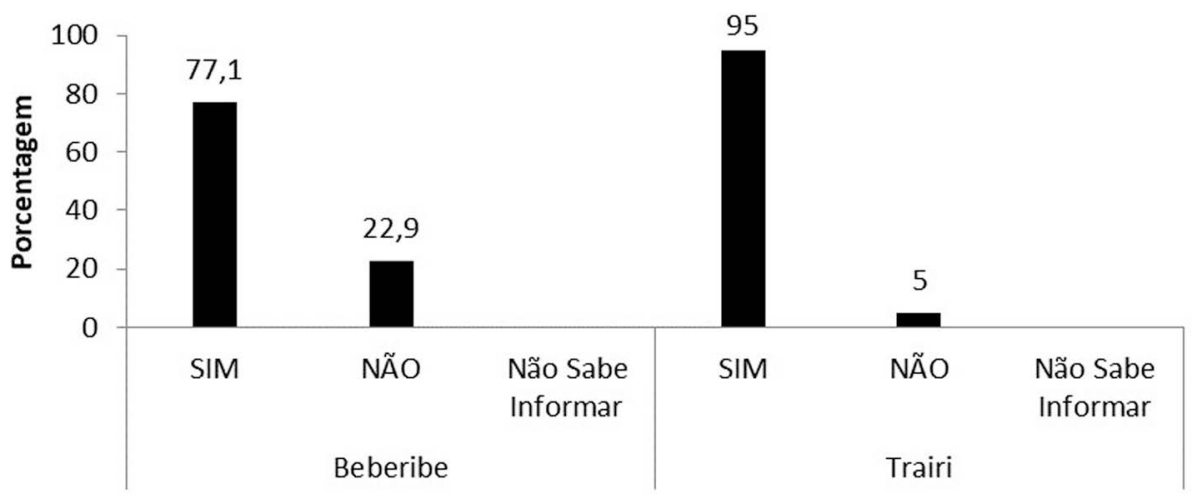

Figura 4 - Percepção das pessoas quanto a produção de ruído das turbinas.

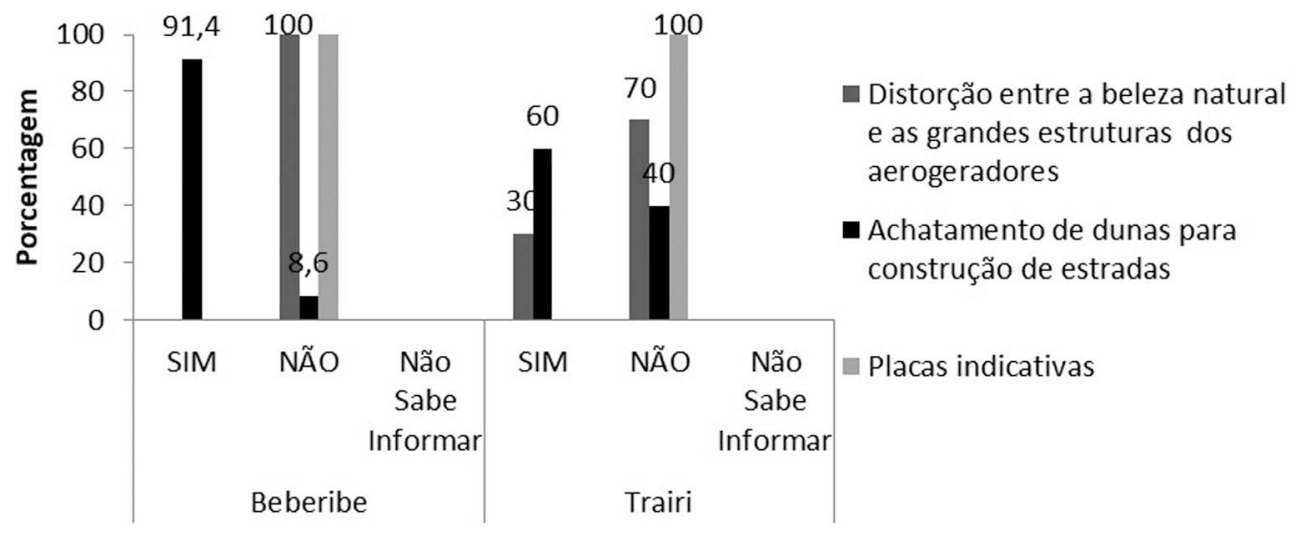

Figura 5 - Descaracterização da paisagem natural. 
passivo do processo de evolução natural e a intensa dinâmica das dunas, com mudança constante de seus aspectos em termos de forma, posição e tamanho. Os aerogeradores cercados por dunas móveis tornam-se uma espécie de barreira para o transporte eólico dos sedimentos, que são contidos nas proximidades das bases. No período de instalação há tentativas de retenção das dunas móveis pela fixação artificial, o que tende a desencadear impactos ambientais negativos. Outro motivo para a contenção das dunas é a tentativa de diminuir o avanço dos sedimentos sobre os aerogeradores, evitando o processo de erosão e degeneração das bases e sobre as estradas de acesso, impedindo o tráfego de veículos.

A degradação das áreas ocorre devido ao desmatamento e a terraplanagem tanto para construção das estradas que dão acesso ao parque e aos aerogeradores dentro das usinas, como também para a construção das bases das torres, podendo ocasionar aterramento de lagoas que surgem entre as dunas, interferência na qualidade da água e destruição de locais preservados. No PEB, como no PEF, ocorreram a devastação, a compactação e o achatamento das dunas, para a instalação das torres no período de implantação dos parques. Atualmente a contenção das dunas se dá através da recuperação da vegetação e da mata ciliar em todo o parque. Segundo a população dos PEB e PEF houve degradação nas áreas de construção dos aerogeradores e das estradas, através do desmatamento e do aplainamento do terreno. Contudo, com a construção dos parques eólicos nos dois municípios, não gerou nenhum efeito sobre as águas e nem sequer destruição de sítios arqueológicos. Na Fig. 6 apresenta-se os percentuais das respostas referentes interferência na paisagem dos parques analisados.

\subsubsection{Impermeabilização e compactação do solo}

Durante o período das obras de construção do PEB e do PEF, houve a inclusão de material sedimentar impermeabilizando e compactando o solo tanto para a construção de estradas de acessos que possibilitam o tráfego de veículos e máquinas, através da construção das estradas de piçarra para formação do leito das vias, quanto para a fincagem das bases dos aerogeradores, ocasionando a substituição dos sedimentos arenosos por estruturas de concreto, apesar de serem alterações pontuais. Quando indagada a população sobre a impermeabilização e a compactação do solo, os entrevistados dos dois parques, responderam que as modificações ambientais foram notadas principalmente no período de chuva, ocasionando queda d'água sobre as residências e pela formação de poças ao longo do percurso de construção das estradas. Os percentuais das respostas referentes à interferência na impermeabilização e compactação do solo estão apresentados na Fig. 7.

\subsection{Avaliação dos aspectos sociais}

\subsubsection{Geração de emprego}

A geração de energia elétrica é uma atividade de capital intensivo e não tem como característica intrínseca a geração de empregos. No entanto, todas as oportunidades de geração de empregos e distribuição de renda devem ser potencializadas. Durante a fabricação e a construção possui um potencial de intensidade de geração de emprego alto e de duração temporária, já no período de operação a intensidade é baixa mais os cargos de trabalhos são permanentes.

Segundo informações da população as oportunidades de empregos para as comunidades foram apenas no

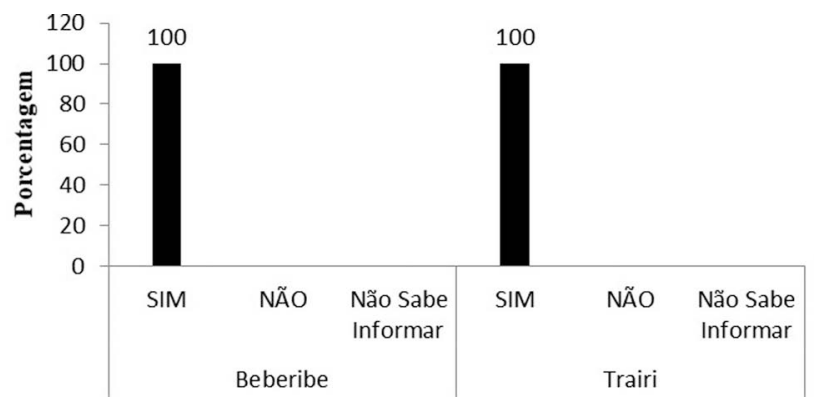

Figura 7 - Impermeabilização e compactação do solo.

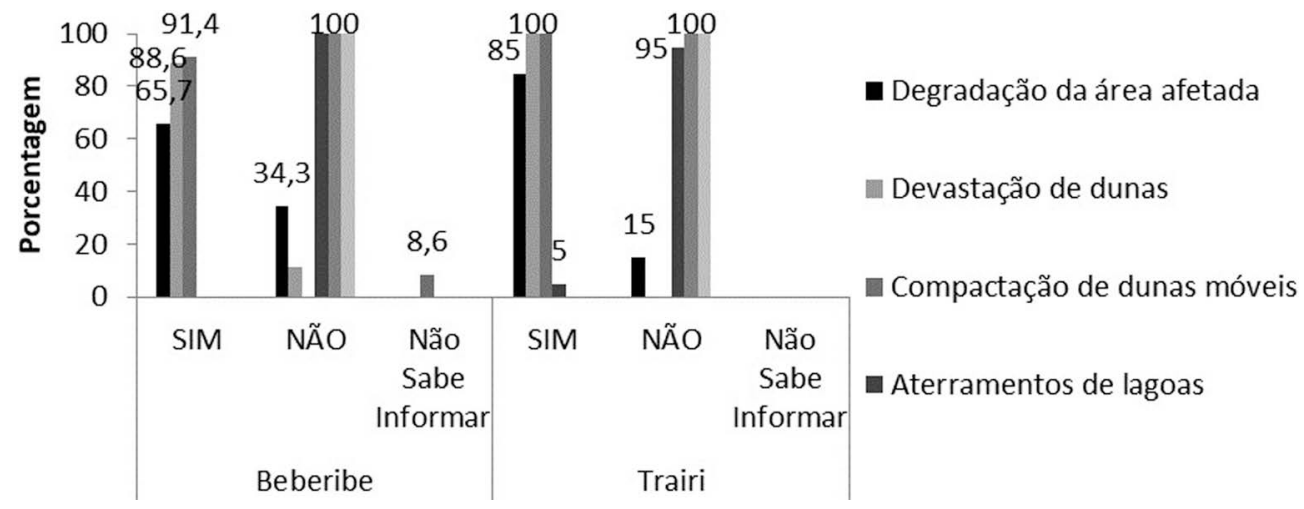

Figura 6 - Interferência na paisagem. 
processo de implantação, atualmente no período de funcionamento a quantidade de pessoas que trabalham nos parques são reduzidos, apenas os funcionários que trabalham na vigilância e segurança. Na Fig. 8 apresenta-se os percentuais das respostas referentes à pergunta: com a presença do parque eólico, trouxe oportunidade de emprego para a comunidade.

\subsubsection{Interferência no cotidiano da população}

Para a população localizada nas adjacências das áreas de influência direta, os impactos mais expressivos provocados pela execução das obras de construção da usina eólica relacionam-se com as interferências no cotidiano das pessoas locais, com a proibição do direito de ir vim pelo local de instalação dos aerogeradores.

Segundo a população de Uberaba (Beberibe), após o parque entrar em operação, os administradores permitem a utilização das estradas que dão acesso ao mar, com as seguintes condições: carros e motos têm que possuir cadastro na portaria e estar de acordo com a legislação, fazendo uso do capacete. A população do Canaã e de Palmeira (Trairi), expõem que pessoas que residem no lugar precisam de autorização para transitar por dentro do parque, já as de outras localidades não são permitidas o acesso. Os percentuais das respostas referentes à interferência no cotidiano da população estão exibidos na Fig. 9.

\subsubsection{Aumento dos índices de eletrificação}

As comunidades que residem nos arredores dos PEB e PEF já eram abastecidas pela rede convencional de energia elétrica. A implantação das usinas não interferiu e nem beneficiou as populações. Na Fig. 10 exibe-se os percentuais das respostas referentes ao aumento dos índices de eletrificação.

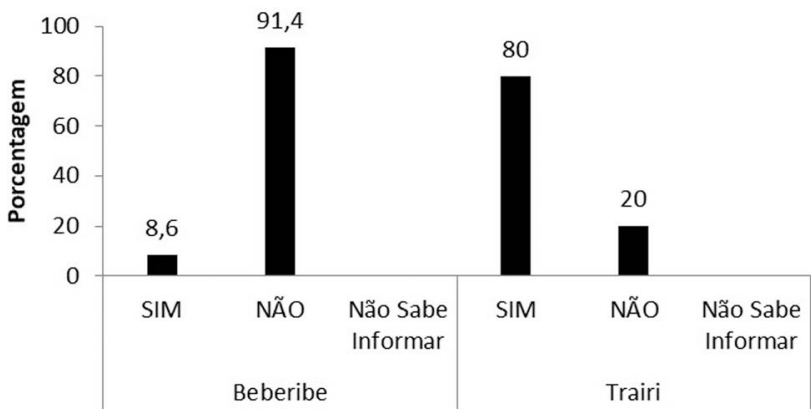

Figura 9 - Interferência no cotidiano da população.

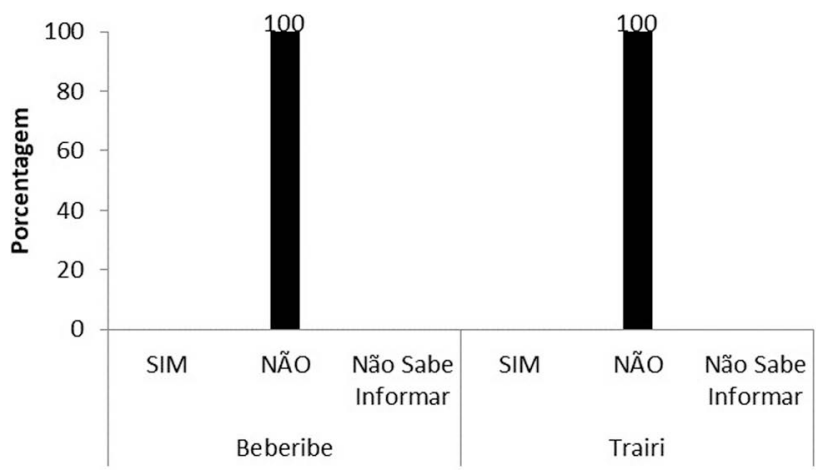

Figura 10 - Aumento dos índices de eletrificação.

\subsubsection{Fissuras em casas}

A rachadura é originada pela acomodação da estrutura no terreno, que pode ocorrer pela vibração e/ou trepidação sucessiva ocasionada pelo excesso de veículos de grande peso trafegando na rua. De acordo com os informes das pessoas que moram próximo à via de acesso ao parque no município de Trairi, devido ao tráfego de veículos algumas residências apresentaram rachaduras, já no município de Beberibe nenhum caso foi detectado. Os

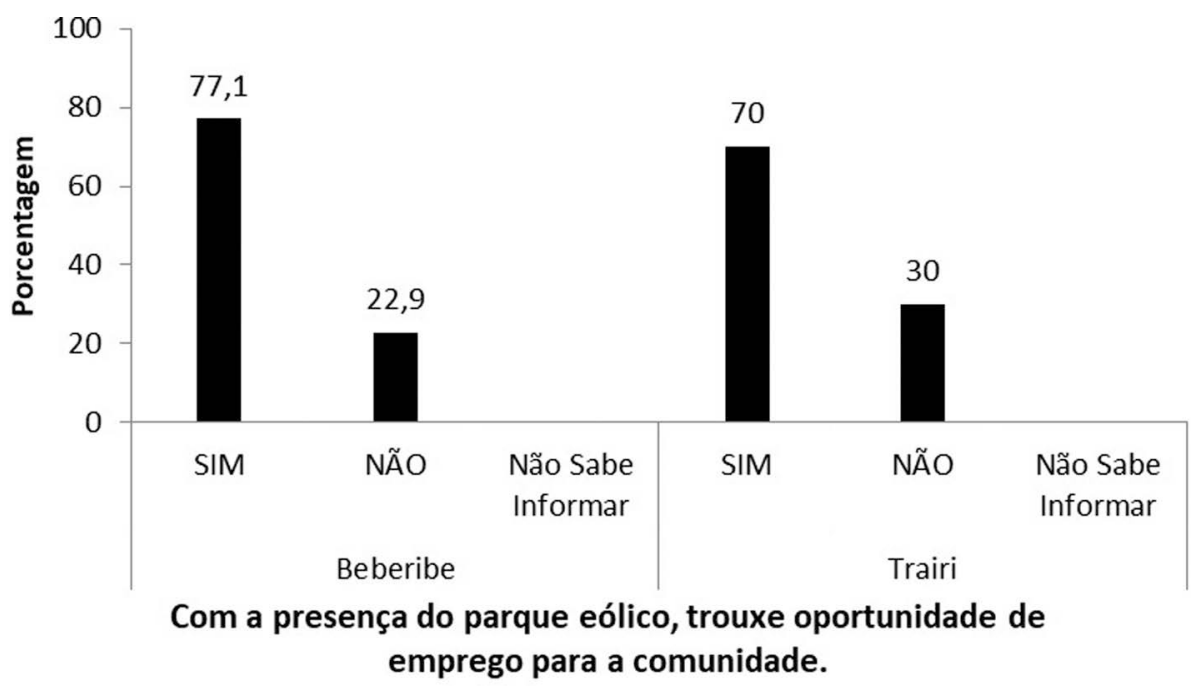

Figura 8 - Geração de emprego. 
percentuais das respostas referentes a fissuras em casas estão retratados na Fig. 11.

\subsubsection{Aumento do risco de acidente}

Durante a construção dos parques há um tráfego constante de carro que pode acarretar riscos, principalmente para as crianças do lugar que são acostumadas a brincar na rua. Em relação a acidente que pode ocorrer, a população pesquisada não possui nenhum registro. Porém a possibilidade levantada pela população de Beberibe, mesmo o parque estando em operação existe os caminhões para reparos e manutenção dos aerogeradores, não isentando nenhuma probabilidade de ocorrência de acidentes. Na Fig. 12 apresenta-se os percentuais das respostas referentes ao aumento do risco de acidentes.

\subsubsection{Interferência eletromagnética}

Os aerogeradores podem refletir as ondas eletromagnéticas, interferindo ou perturbando os sistemas de telecomunicação. Os campos eletromagnéticos de turbinas de vento podem afetar a qualidade de rádio, $\mathrm{TV}$, telefone $\mathrm{e}$ internet. Segundo relatos das pessoas que residem na comunidade de Uberaba, nenhum caso de interferência foi registrado, enquanto que, na comunidade de Canaã e Palmeira, alguns moradores registram a influência nos sistemas de comunicação. Na Fig. 13 apresenta-se os percentuais das respostas referentes à interferência eletromagnética nas redes de comunicação.

\subsubsection{Projeto social para a comunidade}

Na Tabela 1 exibe-se os projetos sociais desenvolvidos pelas usinas eólicas de Beberibe e Fleixeiras I, nos municípios de Beberibe e Trairi, respectivamente.

\subsection{Avaliação dos aspectos econômicos}

Na Fig. 14 apresenta-se em percentagem os impactos segundo o comércio que participou da pesquisa. No comércio de Beberibe e de Trairi foram aplicados quarenta formulários aplicados (vinte para cada município).

Quando indagado os comerciantes do município de Beberibe sobre se a construção do parque resultou no aumento do movimento e do lucro para o seu estabelecimento, $95 \%$ responderam que não, esses mesmos

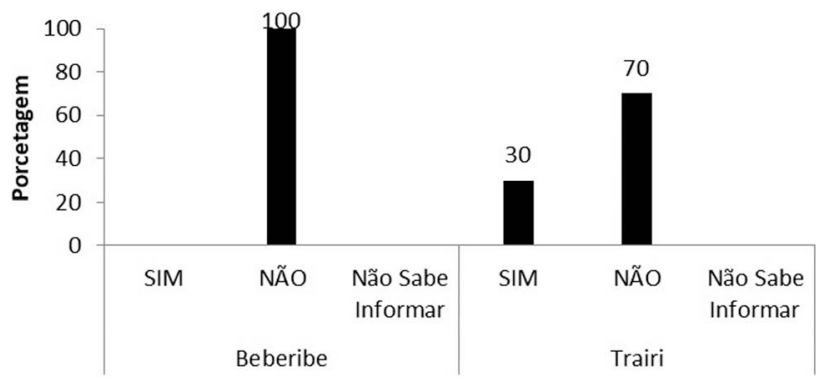

Figura 11 - Fissura em casas.

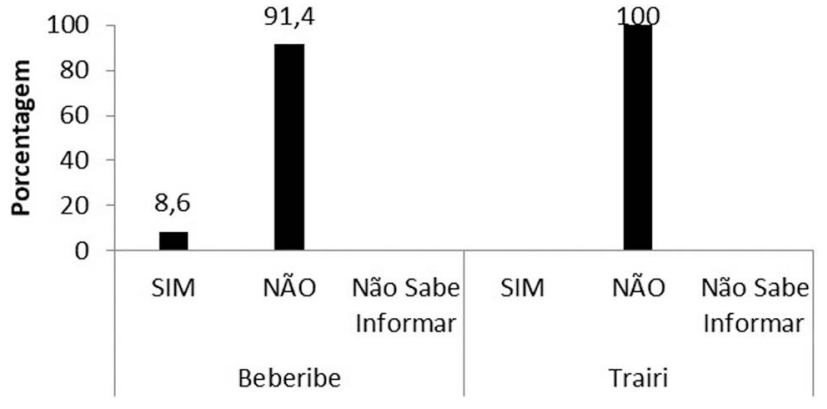

Figura 12 - Aumento do risco de acidente.

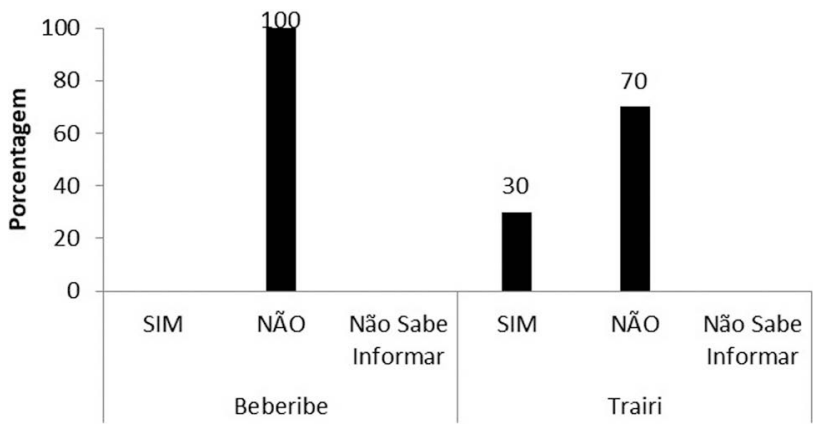

Figura 13 - Interferência eletromagnética.

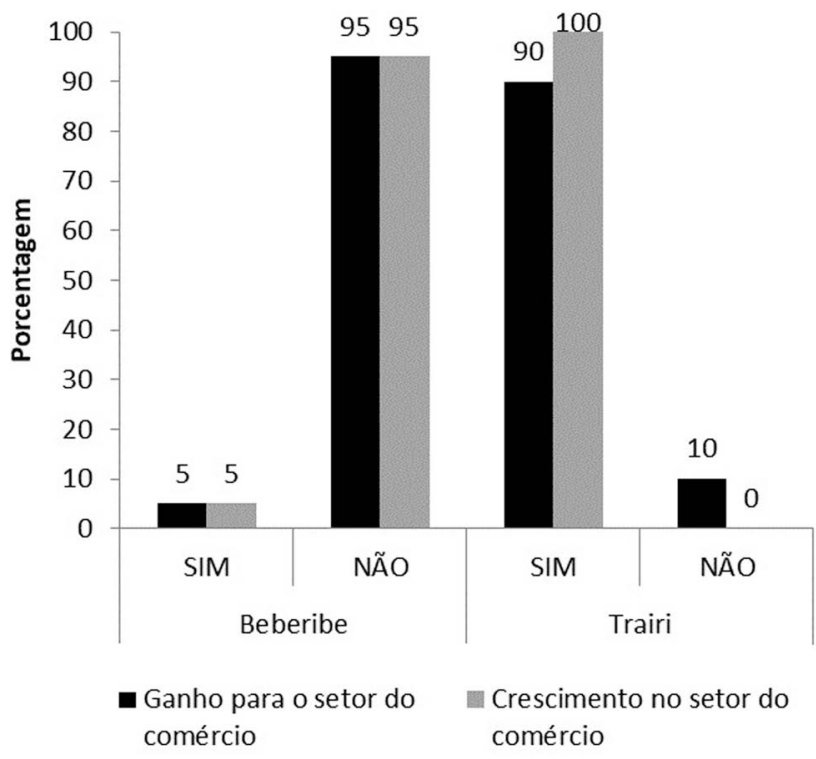

Figura 14 - Impactos econômicos no setor do comércio.

negociantes também responderam que não resultou na abertura de novos estabelecimentos comerciais. Em relação aos impactos no setor do comércio, dos entrevistados $5 \%$ disseram que trouxe benefício, $0 \%$ disseram que trouxe prejuízo e $95 \%$ que não teve nenhuma mudança para o comércio. Isso é justificado pelo tempo de implantação do parque ser mais de dez anos, sendo que, naquela época as pessoas da comunidade e do próprio município 
Tabela 1 - Projetos sociais desenvolvidos pelas usinas eólicas de Beberibe e Fleixeiras I.

\begin{tabular}{|c|c|}
\hline Usina de Beberibe & Usina de Fleixeiras I \\
\hline $\begin{array}{l}\text { Parceria com as escolas e universidades para a realiza- } \\
\text { ção de visitas técnicas ao parque. }\end{array}$ & $\begin{array}{l}\text { Trabalhos com educação ambiental nas escolas, através da capacitação de alunos e professores, } \\
\text { com o projeto "ÉCOMVOCÊ". }\end{array}$ \\
\hline $\begin{array}{l}\text { Projeto de consumo consciente de energia elétrica apli- } \\
\text { cado escolas. }\end{array}$ & $\begin{array}{l}\text { Projeto "Crianças Saudáveis, Futuro Saudável”, iniciado em } 2016 \text {, consiste no tratamento con- } \\
\text { tra verminose e anemia através da aplicação de suplementos, vacinas e vermífugos em aprox- } \\
\text { imadamente } 4500 \text { crianças do ensino básico das escolas localizadas no município de Trairi e nas } \\
\text { proximidades das usinas. }\end{array}$ \\
\hline \multirow[t]{3}{*}{$\begin{array}{l}\text { Apoio à associação dos moradores da comunidade } \\
\text { Uberaba. }\end{array}$} & $\begin{array}{l}\text { Manutenção de acessos, estradas e vias de ligação para melhoria no translado das comunidades } \\
\text { no entorno das usinas, além de obras realizadas para estas comunidades. }\end{array}$ \\
\hline & $\begin{array}{l}\text { Criação de uma associação de catadores de resíduos em Trairi, com capacitações e instruções } \\
\text { junto aos mesmos e criação de um centro de triagem destes resíduos. Reuso de água de pias, } \\
\text { ralos e áreas comuns de associações carentes para irrigação. }\end{array}$ \\
\hline & Projeto de proteção as nascentes dos rios e lagos. \\
\hline
\end{tabular}

quando estavam trabalhando na construção, contribuíam indiretamente para aquecer a economia, no entanto, com a finalização das obras e com os postos de trabalhos perdidos, a geração de energia eólica diretamente não contribui e nem influencia diretamente na economia do munícipio. $\mathrm{O}$ administrador da usina mantém parceria com associação comunitária da localidade de Uberaba, efetuando compras apenas em uma loja do centro da cidade, isso justifica os $5 \%$ que descreveram que traz benefícios.

Quando questionado os comerciantes do município de Trairi sobre se a construção do parque resultou no aumento do movimento e do lucro para o seu estabelecimento, $90 \%$ responderam que sim e $100 \%$ responderam que contribuiu para abertura e o crescimento de novos estabelecimentos comerciais no município. Em relação aos impactos no setor do comércio, dos entrevistados $85 \%$ disseram houveram benefício, $10 \%$ que trouxe prejuízo e $5 \%$ que não teve mudança para o comércio. Pelo tempo de construção da usina ser apenas três anos, o comércio ainda passa por um período de crescimento deixado pelo aquecimento da economia através da construção do parque, ficou claro que além do surgimento, expansão e da melhoria estrutural para atender a nova demanda, os comércios se tornaram locais atrativos para utilização dos próprios moradores da cidade, mantendo a economia em alta.

$\mathrm{O}$ setor de serviço investigado foi composto por pousadas e hotéis pertencentes aos municípios onde foi realizado o estudo. A Fig. 15 apresenta em porcentagem os impactos segundo o setor de serviço que participou da pesquisa. Em Beberibe e em Trairi foram aplicados quarenta formulários aplicados (vinte para cada município).

Quando aplicados os formulários nos hotéis e pousadas do município de Beberibe para saber se a construção do parque resultou no aumento do movimento e do lucro para o seu estabelecimento, $30 \%$ responderam que sim e $70 \%$ responderam que não. Quando perguntado se seu estabelecimento estava preparado em termo de infraestrutura para atender a nova demanda, quando teve início a construção do parque, $20 \%$ responderam que sim, $15 \%$

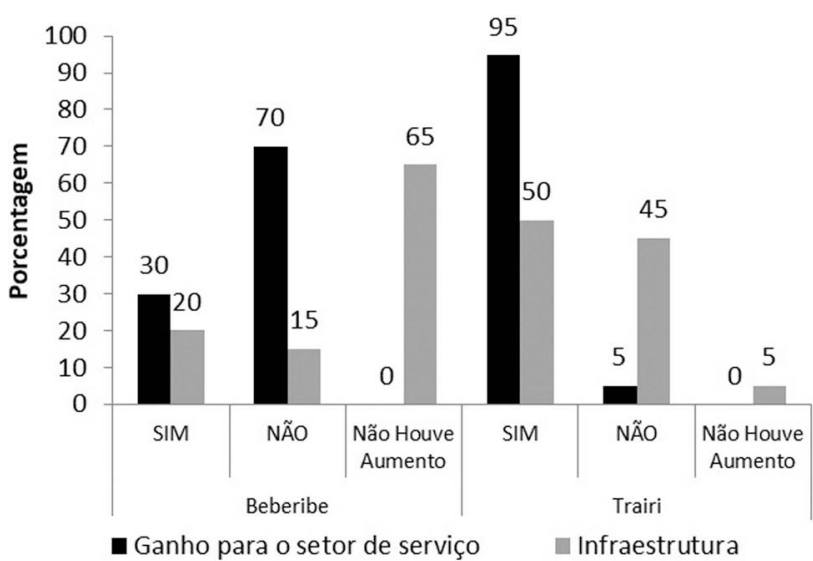

Figura 15 - Impactos econômicos no setor do serviço.

responderam que não e $65 \%$ que não houve aumento, sendo $95 \%$ declararam que não passou por nenhum tipo de ampliação e 5\% por ampliação de pessoas e estruturas. Em relação aos impactos no setor do serviço, a construção do parque eólico trouxe mudança para o campo de serviço no município, $50 \%$ responderam que trouxe benefícios, $50 \%$ nenhuma mudança e $0 \%$ prejuízo.

Quando aplicado os formulários nos hotéis e pousadas do município de Trairi para saber se a construção do parque resultou no aumento do movimento e do lucro para o seu estabelecimento, $95 \%$ responderam que sim e $5 \%$ responderam que não. Quando perguntado se seu estabelecimento estava preparado em termo de infraestrutura para atender a nova demanda, quando teve início a construção do parque, $50 \%$ responderam que sim, $45 \%$ responderam que não e $5 \%$ que não houve aumento no número de pessoas, sendo que, $25 \%$ passaram por ampliação apenas de pessoal, $40 \%$ passou por ampliação estrutural e de pessoas e 35\% não passou por nenhum tipo de ampliação. Em relação aos impactos no setor do serviço, a construção do parque eólico trouxe mudança para o campo de serviço no município, $95 \%$ responderam que trouxe benefícios, $0 \%$ nenhuma mudança e $5 \%$ prejuízo. 
Em ambas as situações, vale destacar quem se hospedava em pousadas e hotéis eram os administradores, os engenheiros e os técnicos responsáveis pelas obras, contudo as pessoas que trabalhavam na execução, devido ao custo da diária e o tempo de permanência, alugavam casas e em alguns casos ficavam em acampamento dentro da própria usina.

Para realização desse trabalho foi aplicado formulário ao gestor de turismo de cada município, buscando conhecer os aspectos econômicos e sociais ocorridos com a chegada do parque eólico. Dessa maneira, podemos perceber através da aplicação do formulário à técnica de turismo da secretaria de turismo e cultura do município de Beberibe e ao gerente de turismo da secretaria de turismo do município de Trairi, que a implantação das usinas eólicas trouxe benefícios, como: valorização de imóveis no entorno do empreendimento, geração de emprego direto e indireto, aumento na demanda por infraestrutura urbana e serviço, aumento na demanda por área de lazer no município, aumento de renda para as pessoas da comunidade, atrações turísticas na região do parque, migração de trabalhadores de outras localidades para trabalhar na usina, crescimento da região e/ou cidade. Na região de Beberibe com a instalação e operação do parque os que mais cresceram foram os pequenos comércios e na região de Trairi foram restaurantes, pousadas e os imóveis alugados para a hospedagem das pessoas que trabalharam na construção do parque.

\subsection{Avaliação dos aspectos tecnológicos}

\subsubsection{Caracterização técnica dos aerogeradores}

O PEF possui uma capacidade instalada de $30 \mathrm{MW}$, constituída de 13 (treze) aerogeradores, modelo SWT 2.3101, com frequência de $60 \mathrm{~Hz}$ da fabricante Siemens, cuja turbina foi certificada pela empresa dinamarquesa Det Norske Veritas, Danmark A/S. o PEB possui uma capacidade instalada de $25 \mathrm{MW}$, constituída de 25 (vinte e cinco) aerogeradores, modelo FUHRLÄNDER FL 1000, com frequência de $60 \mathrm{~Hz}$ da fabricante Fuhrländer $\mathrm{GmbH}$. A Tabela 2 especifica as características técnicas dos equipamentos das usinas.

\subsubsection{Curva de geração de energia elétrica}

Cabe destacar que a fonte de geração de energia eólica apresentou um expressivo desenvolvimento no país ao longo do ano de 2016, ficando responsável pela geração de 33,15 TWh, com uma potência média de 3.772,7 MW médios e o recorde foi em outubro, quando a atingiu a marca de 4.951,3 MW médios. As regiões que mais cresceram foram a Sul com $35 \%$ e a Nordeste com $60 \%$. Em comparação com 2015, a produção de energia dos ventos foi superior em $55 \%$. No estado do Ceará, a potência média da fonte eólica foi de 667,958 MW médios e o recorde foi em novembro, quando atingiu a marca de
Tabela 2 - Características dos equipamentos das usinas de Fleixeiras I e Beberibe.

\begin{tabular}{lcc}
\hline Especificação técnica & Usina de Fleixeiras I & Usina de Beberibe \\
\hline Modelo & SWT 2.3-101 & FUHRLÄNDER FL 1000 \\
Fabricante & Siemens & Fuhrländer GmbH \\
Potência nominal & $2.3 \mathrm{MW}$ & $1 \mathrm{MW}$ \\
Diâmetro do rotor & $101 \mathrm{~m}$ & $54 \mathrm{~m}$ \\
Altura da torre & $80 \mathrm{~m}$ & $70 \mathrm{~m}$ \\
Controle de potência & Pitch & Pitch \\
Velocidade de Cut-In & $3,0 \mathrm{~m} / \mathrm{s}$ & $2,5 \mathrm{~m} / \mathrm{s}$ \\
Velocidade nominal & $12 \mathrm{~m} / \mathrm{s}$ & $13 \mathrm{~m} / \mathrm{s}$ \\
Velocidade de Cut-Out & $25,0 \mathrm{~m} / \mathrm{s}$ & $25,0 \mathrm{~m} / \mathrm{s}$ \\
Fator de capacidade & $48,2 \%$ & $35 \%$ \\
\hline
\end{tabular}

Fonte: Adaptado do RIMA, 2011; RIMA, 2001.

$1.038 \mathrm{MW}$ médios. A Fig. 16 ilustra a potência média verificada em 2016 no Brasil e no Estado do Ceará.

A usina eólica de Beberibe no ano de 2016 gerou uma produção anual de energia de $89,49 \mathrm{GWh}$ (equivale a uma potência média de 7.457,5 MW médio), já na usina eólica de Fleixeiras I a produção anual de energia foi de 125,78 GWh (equivale a uma potência média de 10.481,7 MW médio). A Fig. 17 revela a produção mensal da capacidade de geração de energia bruta em GWh dos parques eólicos de Beberibe e Fleixeiras I no ano de 2016.

3.4.3. Emissão de Dióxido de Carbono $\left(\mathrm{CO}_{2}\right)$ evitada na geração de energia eólica

Na Fig. 18 exibe-se a quantidade de $\mathrm{CO}_{2}$ evitada mensalmente com a geração de energia eólica no ano de 2016 no Brasil, pode-se destacar a quantidade evitada no ano de 17,81 milhões de Toneladas. Conforme a ABEEólica (2017), a emissão de $\mathrm{CO}_{2}$ evitada no ano de 2016 corresponde à quantidade produzida por praticamente toda a frota de automotores da Cidade de São Paulo.

No âmbito de Estado do Ceará, a redução de $\mathrm{CO}_{2}$ evitada para o meio ambiente no ano de 2016 devido à geração de energia proveniente da eólica foi de 243.410,85 (tonelada/ano). No PEB foi de 4.335,72 (tonelada/ano) e no PEF foi de 6.094,00 (tonelada/ano). A Fig. 19 ilustra a quantidade de $\mathrm{CO}_{2}$ evitada por meses do ano de $2016 \mathrm{em}$ ambos os parques.

Os benefícios alcançados com a substituição de combustíveis fósseis por fontes renováveis são inúmeros. É importante citar alguns deles para se ter uma noção da abrangência desses benefícios. Pode-se destacar, portanto, a garantia da sobrevivência da nossa espécie e de muitos seres vivos por mais tempo, a melhoria da qualidade de vida e a continuidade da operacionalização dos processos produtivos, pois as empresas deixariam de depender de combustíveis esgotáveis (Lima et al. 2006).

Destaca-se também que a energia produzida pelos ventos é renovável, possui baixo impacto ambiental, 


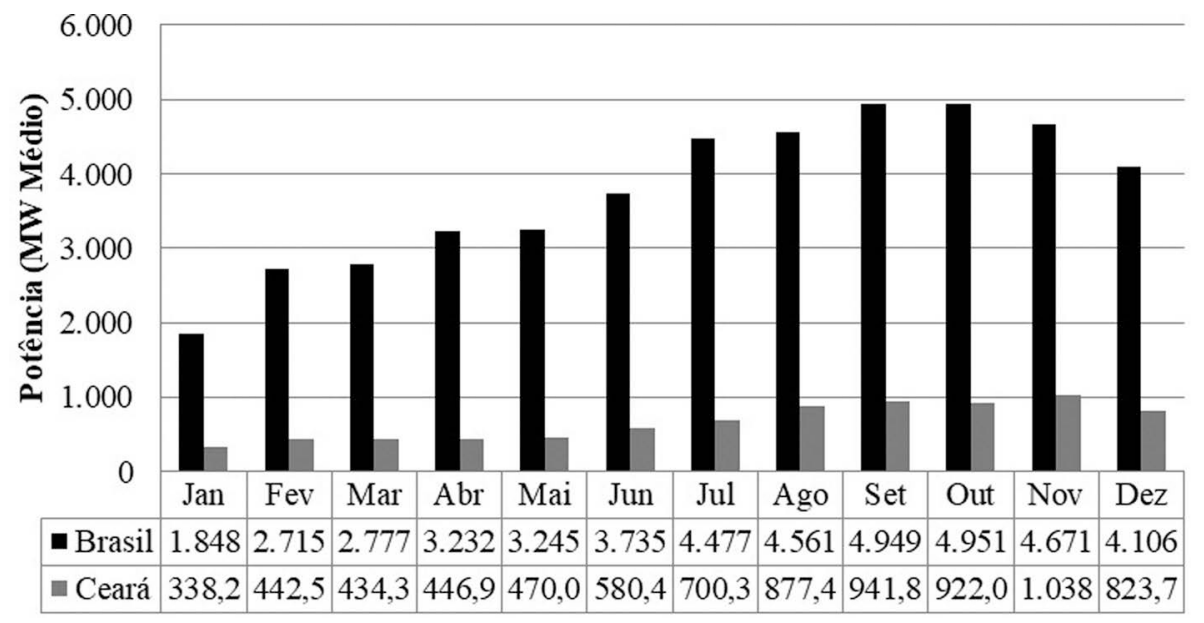

Figura 16 - Geração média verificada no Brasil e no Estado do Ceará em 2016 pela fonte eólica. Fonte: Adaptado do CCEE, Abeeólica, 2017.

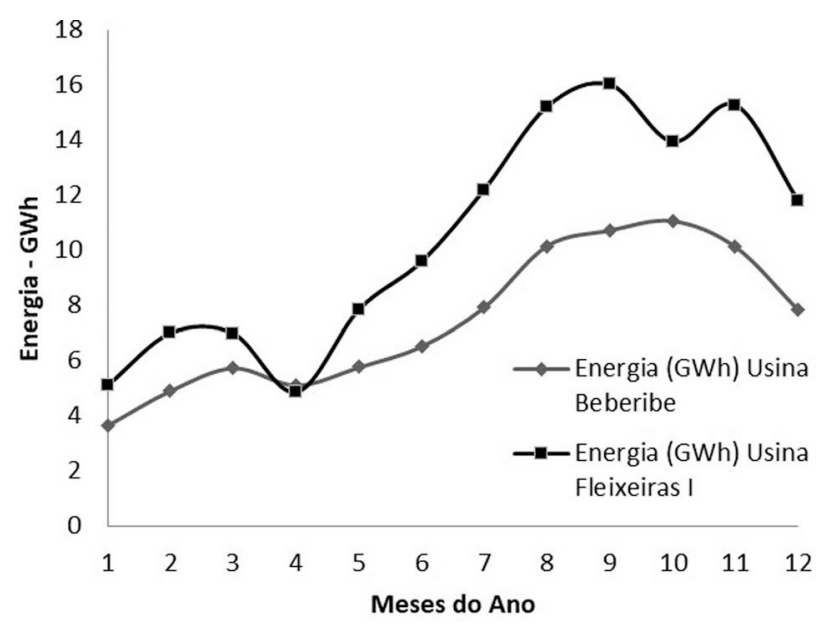

Figura 17 - Geração de energia da usina eólica Beberibe e Fleixeiras I no ano de 2016. permite no local de instalação dos aerogeradores a reutilização das terras pelos proprietários para cultivo no setor da agropecuária, como ocorre nos parques eólicos estudados de Beberibe e Fleixeiras I. Podem ainda contribuir na comercialização de fonte de energia competitiva, promovendo um melhor custo benefício na conta de energia.

\section{Conclusões}

A implantação de parques eólicos nas zonas litorâneas do Estado do Ceará tem apresentado um rápido crescimento. Nessa pesquisa foi possível perceber que os principias impactos negativos são ocasionados durante a fase implantação das usinas, em alguns casos, prolonga-se pelo período de funcionamento. Observa-se um acúmulo de impactos, sobretudo para as comunidades que moram próximas dos parques eólicos, especialmente sobre

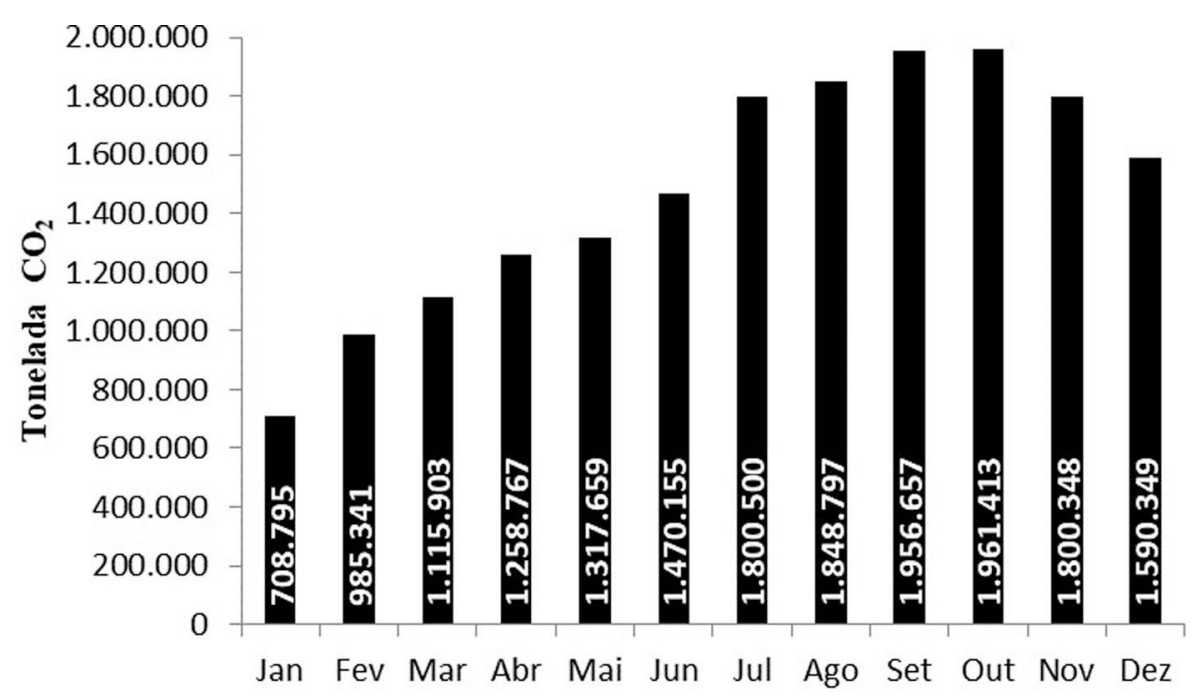

Figura 18 - Quantidade de $\mathrm{CO}_{2}$ mensal evitada no Brasil pela fonte eólica no ano de 2016. Fonte: Adaptado da ANEEL, MCTI, ABEEólica, 2017. 


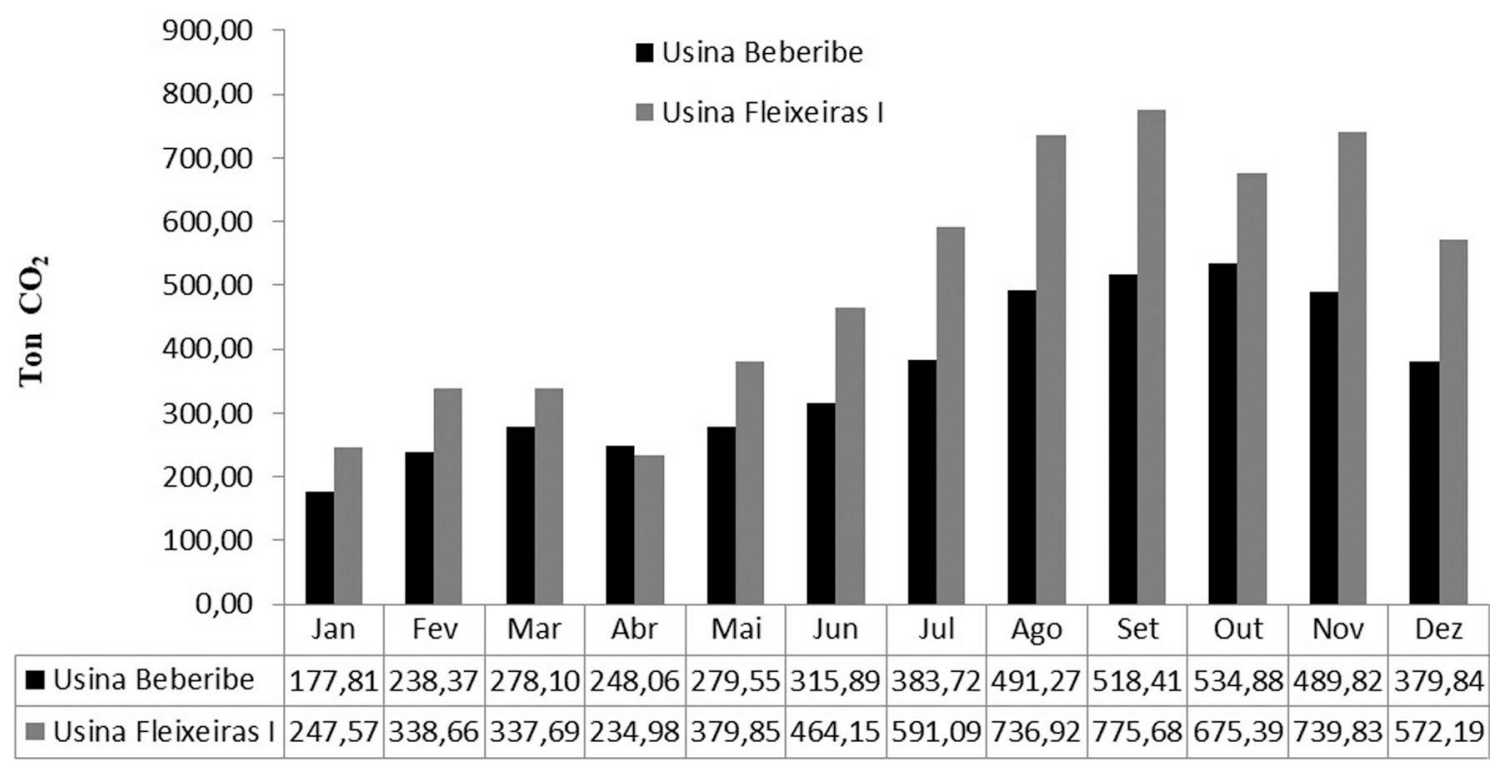

Figura 19 - Quantidade de $\mathrm{CO}_{2}$ mensal evitada no parque eólico de Beberibe e Fleixeiras I no ano de 2016.

aquelas que já possuem uma cultura organizacional consolidada.

Os principais impactos ambientais ocasionados com a instalação dos PEB e PEF estão ligados à interferência na paisagem, como a terraplanagem, a impermeabilização e a compactação do solo; o achatamento, degradação e devastação dos campos de dunas; a suspensão, diminuição e substituição da vegetação. Os impactos dessa natureza ocorrem devido à necessidade de fincagem das torres e construção das estradas de acessos para passagem dos maquinários e equipamentos.

As vias de acesso para os parques são de estradas carroçáveis, contribuindo para um rápido desgaste das vias e da poeira ocasionada com o trânsito de carro e caminhões, foi o aspecto negativo mais reclamado pelos respondentes do questionário aplicado, em virtude de ocasionar doenças de caráter respiratório e também de sujeiras nas residências. Em relação à geração de ruídos pelas turbinas dos aerogeradores instaladas nos PEB e PEF não foi possível sua mensuração, pois não se conseguiu equipamentos adequados a essa medição.

No parque de Fleixeiras I identificou-se que alguns impactos foram provocados na fauna alada e terrestre. Apesar de citado, esse impacto não foi possível mensurar, pois são de difícil comprovação, seria necessário um inventário antes da instalação do parque. Os impactos sociais estão associados com a geração de emprego, essa oportunidade é apenas durante a fase de implantação deixando de existir ou havendo em pequenas quantidades após a conclusão dos parques. Privatização de trechos do litoral, entre as comunidades litorâneas e a faixa de praia, dificultando o acesso da população às usinas. Rachadura nas casas provocadas pela movimentação dos caminhões pesados pelas vias de proximidade das residências e a interferência eletromagnética nas redes de comunicação.

Os impactos econômicos ligados ao setor do comércio são mais sentidos durante a construção dos parques devido ao número de empregos gerados, tanto para a população do município, como também para pessoas de outros municípios ou até mesmo de outros estados para trabalhar nas usinas, contribuindo para alavancar o crescimento dos estabelecimentos existentes, bem como a abertura de novos estabelecimentos comerciais. O setor de prestação de serviço, como hotéis e pousadas também apresentaram um crescimento durante a instalação das usinas devido à hospedagem realizadas nos hotéis da região, como também alugueis de residências para instalação dos funcionários. Como o PEF é mais recente, esses impactos ainda são sentidos pela população de Trairi, todavia, a população de Beberibe acredita que não interfere diretamente no comércio e no setor de serviço do município.

Os impactos tecnológicos estão ligados diretamente à geração de energia elétrica, uma vez que, durante a geração por fonte eólica não é necessário à utilização de outros recursos naturais, como a água e de nenhuma fonte de recursos inesgotáveis do planeta. É considerada uma fonte renovável e alternativa, devido a não emissão de $\mathrm{CO}_{2}$ para a atmosfera, contribuindo para diminuição dos GEE e também para a redução dos impactos extremos das mudanças climáticas. Diante dos resultados obtidos, constatase que a implantação do parques eólicos é uma possibilidade para geração de energia com menores consequências ao meio ambiente em comparação com as outras fontes, porém, para que os impactos ocorridos com a implantação dos parques sejam minimizados, sugere-se que as vias de acesso aos parques recebam uma camada de proteção para 
redução de poeira e que o trânsito de carro aconteça em baixa velocidade, bem como se construam vias de acesso que não seja pelas comunidades, principalmente pelo tráfego de veículos pesados; o acesso pelos campos de dunas seja liberado para as pessoas da comunidade, não sendo necessária a permissão para a mobilidade sobre as dunas; é necessário monitoramento dos ruídos produzidos pelos aerogeradores e também o acompanhamento constante sobre a fauna e a flora das regiões, no sentido de manter ou restabelecer as condições naturais da área. Envolvendo e consultando a população sobrem os assuntos que diretamente ou indiretamente possam afetar a população do entorno.

\section{Referências}

ANENBERG, S.; BALAKRISHNAN, K.; JETTER, J.; MASERA, O.; MEHTA, S.; MOSS, J.; RAMANATHAN, V. Cleaner Cooking Solutions to Achieve Health, Climate, and Economic Cobenefits. Environ. Sci. Technol. v. 47, n. 9, p. 3944-3952, 2013.

CUADRA, L.; CAMPO-ESTRELLA, I.; ALEXANDRE, E.; SALCEDO-SANZ, S. A study on the impact of easements in the deployment of wind farms near airport facilities. Renewable Energy, v. 135, p. 566-588, 2019.

DRUMM, F.C.; GERHARDT, A.E.; FERNANDES, G.D.; CHAGAS, P.; SUCOLOTTI, M.S.; et al. Poluição Atmosférica Proveniente da Queima de Combustíveis Derivados do Petróleo em Veículos Automotores. Revista Eletrônica em Gestão, Educação e Tecnologia Ambiental, v.18 n.1, p. 66-78, abr. 2014.

FARIAS, L.T.S. Energia Alternativa: Impactos da Energia Eólica para a Comunidade Local. Revista Especialize On-line IPOG - Goiânia, v. 1/2016, n. 11, jul. 2016.

FERNANDES, B.; ARRAIS JUNIOR, E. Impactos Ambientais dos Parques Eólicos na Região da Costa Branca Potiguar. Anais do Encontro de Computação do Oeste Potiguar ECOP/UFERSA 2017. Pau dos Ferros/RN, v.1, p. 149-156, jun. 2017.

FREITAS, G.C.; DATHEIN, R. As energias renováveis no Brasil: uma avaliação acerca das implicações para o desenvolvimento socioeconômico e ambiental. Revista Nexos Econômicos, v. 7, n. 1, p. 71-94, 2013.

FREITAS, J.C.; SANTOS, J.A.; CÂNDIDO, S.M.; RAMOS, D. P. Energias Renováveis, Clima e Mudanças Climáticas. Revista Gestão e Sustentabilidade Ambiental, v. 4, n. especial, p. 317-329, 2015.

JABER, S. Environmental Impacts of Wind Energy. Journal of Clean Energy Technologies, v. 1, n. 3, p. 1532-1539, 2013.

LIMA, M.S.O.; REBALATTO, D.A.N.; SAVI, E.M.S. O Papel das Fontes Renováveis de Energia na Mitigação da Mudança Climática. Universidade Estadual Paulista Júlio de Mesquita Filho (UNESP) - Simpósio de Engenharia de Produção, Anais do XIII SIMPEP, São Paulo, 2006.

NASCIMENTO, R.S.; ALVES, G.M. Fontes Alternativas e Renováveis de Energia no Brasil: Métodos e Benefícios Ambientais. XX Encontro Latino Americano de Iniciação
Científica, XVI Encontro Latino Americano de Pós-Graduação e VI Encontro de Iniciação à Docência - Universidade do Vale do Paraíba, 2016.

RELATÓRIO DE IMPACTO AMBIENTAL. Relatório de Impacto Ambiental Volume I/II. Espaço Técnico - Serviços Geológicos LTDA. Biblioteca da Superintendência Estadual do Meio Ambiente (SEMACE), 2001.

TOLMASQUIM, M.T. Energia Renovável: Hidráulica, Biomassa, Eólica, Solar, Oceânica. EPE: Rio de Janeiro, 2016. 452p.

WANG, S.; WANG, S. Impacts of Wind Energy on Environment: A Review. Renewable and Sustainable Energy Reviews, v. 49, p. 437-443, Set. 2015.

\section{Endereços de Internet}

AGÊNCIA NACIONAL DE ENERGIA ELÉTRICA. Energia Eólica. 2016. Disponível em: http://www2.aneel.gov.br/ aplicacoes/atlas/pdf/06-energia_eolica(3).pdf. Acesso em: 25 fev. 2017.

ASSOCIAÇÃO BRASILEIRA DE ENERGIA EÓLICA. Boletim Anual de Geração Eólica 2017. Disponível em: http:// abeeolica.org.br/dados-abeeolica/. Acesso 11 de mar. 2019.

ASSOCIAÇÃO BRASILEIRA DE ENERGIA EÓLICA. Dados Mensais de Geração 2017. Disponível em: http://www. abeeolica.org.br/wp-content/uploads/2017/01/Dados-Men sais-ABEEolica-01.2017-1.pdf. Acesso em: 27 out. 2017.

ASSOCIAÇÃO BRASILEIRA DE ENERGIA EÓLICA. Boletim Anual de Geração Eólica 2016. Disponível em: http:// www.abeeolica.org.br/wp-content/uploads/2017/05/ 424_Boletim_Anual_de_Geracao_Eolica_2016_Alta.pdf. Acesso em: 25 maio 2017.

BRASIL. MINISTÉRIO DE CIÊNCIA, TECNOLOGIA E INOVAÇÃO. Fatores de Emissão de $\mathrm{CO}_{2}$ do Sistema Interligado Nacional do Brasil. 2016. Disponível em: http:// www.mct.gov.br/index.php/content/view/72764/Fatores_ de_Emissao_de_CO_sub_2_sub_do_Sistema_Interliga do_Nacional_do_Brasil.html. Acesso em: 02 jul 2016.

CÂMARAA DE COMERCIALIZAÇÃO DE ENERGIA ELÉTRICA. Leilões. Disponível em: https://www.ccee.org.br/ search/query/search?q=leiloes. Acesso em: 26 out. 2017.

EIA (U.S. ENERGY INFORMATION ADMINISTRATION). Wind Energy and the Environment. Disponível em: https://www.eia.gov/energyexplained/index.php?page=win d_environment. Acesso 11 de mar. 2019.

EMPRESA DE PESQUISA ENERGÉTICA (EPE). Balanço Energético Nacional 2018: Ano base 2017 / Empresa de Pesquisa Energética. Rio de Janeiro: EPE, 2018. Disponível em: http://epe.gov.br/pt/publicacoes-dados-abertos/ publicacoes/balanco-energetico-nacional-2018. Acesso em 11 mar. 2019

RELATÓRIO DE IMPACTO AMBIENTAL. Central Eólica Flexeiras Ltda. Disponível em: http://www.semace.ce.gov. br/wp-content/uploads/2012/06/RIMA_Fleixeiras_PDF. pdf. Acesso em: 06 jul. 2017.

License information: This is an open-access article distributed under the terms of the Creative Commons Attribution License (type CC-BY), which permits unrestricted use, distribution and reproduction in any medium, provided the original article is properly cited. 